\title{
Perencanaan Sistem Mekanikal Elektrikal dan Plumbing (MEP) pada Gedung Bertingkat
}

\author{
${ }^{(1)}$ Muhammad Marsudi, ${ }^{(2)}$ Gusti Rusydi Furqon Syahrillah \\ ${ }^{(1)}$ Prodi Teknik Industri, ${ }^{(2)}$ Prodi Teknik Mesin Fakultas Teknik, Universitas Islam \\ Kalimantan MAB \\ Jl. Adhiyaksa No. 2 Kayu Tangi, Banjarmasin \\ Email:muhmarsudi@gmail.com,rani_rusdi@yahoo.com
}

\begin{abstract}
ABSTRAK
Pembangunan suatu gedung dengan penggunaannya dimaksudkan untuk tempat kegiatan manusia sangatlah penting diperhatikan dari segi atau aspek keselamatan dan kenyamanan. Denga kata lain , kenyamanan dan keselamatan bagi pekerja/pegawai/karyawan yang bekerja di suatu gedung harus benar-benar diperhitungkan sejak bangunan itu dibangun. Kenyaman dan keselamatan di dalam gedung terkait erat dengan faktor fasilitas atau sistem Mekanikal Elektrikal Plumbing (MEP) yang ada di gedung tersebut. Masih banyak orang yang belum memahami secara utuh tentang perencanaan sistem MEP yang benar. Dan berdasarkan pemikiran tersebut maka paper ini akan membahas perencanaan sistem MEP pada gedung perkantoran bertingkat dua, dengan maksud memberikan sedikit gambaran bagaimana perencanaan sistem MEP yang benar.
\end{abstract}

Kata Kunci : gedung bertingkat, mekanikal, plumbing, sistem MEP

\section{PENDAHULUAN}

Pembangunan suatu bangunan atau bisa juga disebut sebagai proyek pembangunan gedung adalah pekerjaan multidisiplin bidang keteknikan. Bangunan yang dibangun baik itu bangunan sederhana maupun bangunan gedung bertingkat, untuk keperluan perumahan tempat tinggal, pertokoan, maupun perkantoran dan lainnya, semuanya itu pasti melibatkan tenaga akhli dibidang Teknik Sipil, Teknik Mesin,Teknik Elektro, dan Teknik Arsitektur. Teknik Sipil bertanggung jawab agar fisik bangunan dapat terrealisasi, Teknik Arsitektur bertanggung jawab akan keindahan dan estetika bangunan, namun semua itu tidaklah cukup jika bangunan tersebut tidak dapat difungsikan dengan baik. Disinilah tugas dan peran Teknik Mesin dan Teknik Elektro, yaitu agar bangunan yang dibangun dapat berfungsi sesuai dengan maksud pembangunannya.

Diperlukannya tenaga akhli Teknik Mesin dan Teknik Elektro ini tekait dengan sistem Mekanikal Elektrikal Plumbing (MEP) yang harus terpasang di fisik bangunan tersebut, sehingga dengan adanya sistem MEP maka bangunan dapat difungsikan. Sebagai contoh, kita dapat membayangkan bagaimana suatu bangunan dapat berfungsi dan ditempati jika tidak ada aliran listrik dan fasilitas air di dalam bangunan tersebut. Tentu saja bangunan tersebut tidak dapat difungsikan walau seindah bagaimanapun bangunannya.

Sistem MEP sangat besar pengaruhnya terhadap biaya keseluruhan yang terkait dengan pembangunan dan pengoperasionalan suatu bangunan [1, 2]. Secara umum sistem mekanikal terdiri dari sistem-sistem pemadam 
kebakaran, pendingin udara atau AC (air conditioning), dan sistem transportasi vertikal. Sistem elektrikal terdiri dari sistem-sistem listrik arus kuat, penangkal petir, telepon, tata suara, proteksi kebakaran, jaringan komputer, master televise, dan sistem CCTV. Sedangkan untuk sistem plumbing terdiri dari sistem-sistem pembuangan air limbah, venting, air hujan, dan sistem air bersih $[3,4,5]$.

Banyak yang belum memahami secara benar tentang pentingnya MEP serta prosedur perencanaannya. Berdasarkan hal terebut maka studi kasus yang dilakukan pada perencanaan gedung Kantor $\mathrm{X}$ telah dijadikan objek pada studi ini. Tujuannya adalah untuk memberikan pemahaman yang benar tentang perencanaan sistem MEP pada gedung bertingkat. Pada artikel ini untuk sistem mekanikal hanya dibahas tentang sistem AC, untuk sistem elektrikal akan dibahas masalah sistem arus kuat untuk penerangan yang dalam hal ini adalah jumlah titik lampu atau titik cahaya. Sedangkan untuk sistem plumbing hanya akan dibahas masalah keperluan air bersih, kapasitas tangki air, dan ukuran pipa air bersih yang diperlukan

Dalam perencanaan MEP ada beberapa rumus yang digunakan dan dapat dijelaskan berikut ini $[6,7,8,9]$.

- Menentukan indeks ruangan / indeks bentuk.

$$
\mathrm{k}=\frac{p \times l}{h(p+l)}
$$

dalam hal ini

$\mathrm{k}=$ indeks ruang $(\mathrm{m})$

$\mathrm{p}=$ Panjang Ruangan $(\mathrm{m})$

$l=$ Lebar Ruangan $(\mathrm{m})$

$h=$ tinggi ruangan dikurangi defisiasi

(m)
- Menentukan jumlah titik cahaya.

$$
\mathrm{n}=\frac{E \times A}{\eta \times \Phi \times d}
$$

dalam hal ini

$\mathrm{n}=$ Jumlah Armature

$\mathrm{E}=$ Intensitas Penerangan (Lux)

$\mathrm{A}=$ Luas Ruangan $\left(\mathrm{m}^{2}\right)$

$\eta=$ Rendament / efisiensi yang

didapat

dari nilai indeks ruangan $(\mathrm{k})$

$\Phi=$ Flux Cahaya (Lumen)

$\mathrm{d}=$ Defisiasi $(0.8)$

$\mathrm{h}=$ Tinggi ruangan

- Menentukan kapasitas pendingin udara (AC) di setiap ruangan.

Ada dua perumusan yang dapat digunakan dalam menetapkan kapasitas AC yaitu diasumsikan $500 \mathrm{BTU} / \mathrm{h}$ untuk setiap meter luasan, dan satu rumusan lainnya adalah:

$(\mathrm{WxHxIxLxE}) / 60=$ kebutuhan

BTU

Dalam hal ini:

$$
\begin{aligned}
& \mathrm{L}=\text { panjang }(\mathrm{ft}) \\
& \mathrm{W}=\text { lebar }(\mathrm{ft}) \\
& \mathrm{H}=\text { tinggi }(\mathrm{ft}) \\
& \mathrm{I}, \mathrm{E}=\text { faktor ruang }
\end{aligned}
$$

- Menentukan kebutuhan-kebutuhan akan air perhari, rata-rata, pada jam puncak, dan kebutuhan air pada menit puncak.

$$
\begin{aligned}
& \mathrm{Q}_{\min }=(\mathrm{n}) \times \mathrm{Q}_{\text {std }} \\
& \mathrm{Q}_{\mathrm{d}}=(100 \%+20 \%) \times \mathrm{Q}_{\mathrm{mi}} \\
& \mathrm{Q}_{\mathrm{h}}=\mathrm{Q}_{\mathrm{d}} / \mathrm{T} \\
& \mathrm{Q}_{\mathrm{hmax}}=\left(\mathrm{C}_{1}\right) \times\left(\mathrm{Q}_{\mathrm{h}}\right) \\
& \mathrm{Q}_{\operatorname{mmax}}=\left(\mathrm{C}_{2}\right) \times\left(\mathrm{Q}_{\mathrm{h}}\right) / 60
\end{aligned}
$$


$\mathrm{Q}_{\operatorname{mmax}}=$ kebutuhan air pada menit puncak

$\mathrm{n}=$ jumlah penghuni dalam bangunan

$\mathrm{Q}_{\text {std }}=$ kebutuhan air perhari menurut standar

$\mathrm{T}=$ jumlah jam pemakaian dalam sehari

$\mathrm{C}_{1}, \mathrm{C}_{2}=$ factor koreksi

- Menentukan kapasitas tangki air atas.

$$
\mathrm{V}_{\mathrm{E}}=\left(\mathrm{Q}_{\operatorname{mmax}}-\mathrm{Q}_{\mathrm{hmax}}\right) \mathrm{T}_{\mathrm{p}}+\mathrm{Q}_{\mathrm{pu}} \mathrm{x} \mathrm{T}_{\mathrm{pu}}
$$

dalam hal ini:

$\mathrm{V}_{\mathrm{E}}=$ Kapasitas efektif tangki atas (liter)

$\mathrm{Q}_{\operatorname{mmax}}=$ Kebutuhan puncak (liter/ menit)

$\mathrm{Q}_{\text {hmax }}=$ Kebutuhan jam puncak

(liter/menit

$\mathrm{Q}_{\mathrm{pu}}=$ Kapasitas pompa pengisi (liter/menit) $\quad \mathrm{T}_{\mathrm{p}}=$ Jangka waktu kebutuhan puncak (menit) $\mathrm{T}_{\mathrm{pu}}=$ Jangka kerja pompa pengisi (menit)

- Menentukan diameter pipa air dari pompa ke Roof Tank (tangki atas).

Debit pengaliran yang di rencanakan dari pompa menuju ke roof tank atau disimbolkan dengan $\mathrm{Q}_{\text {alir }}$ dapat dirumuskan:

$\mathrm{Q}_{\mathrm{alir}}=\mathrm{V}_{\mathrm{E}} / \mathrm{T}_{\mathrm{pu}}$

$$
\mathrm{D}_{\text {pipa }}=\left\{\left(4 \times \mathrm{Q}_{\text {alir }}\right) /(\pi \mathrm{x} v)\right\}^{0.5}
$$

dalam hal ini $\mathrm{D}_{\text {pipa }}$ adalah diameter pipa air dari pompa ke tangki atas, sedangkan $\mathrm{v}$ adalah kecepatan rata-rata aliran air yang biasanya ditetapkan berdasarkan nilai standar yang disarankan.

\section{METODE PENELITIAN}

Dalam studi ini pertama kali yang perlu dilakukan adalah observasi dan pengumpulan data di lapangan. Setelah data terkumpul maka selanjutnya dilakukan perhitungan perencanaan mengenai sistem MEP standar yang harus di-instalasikan pada gedung Kantor $\mathrm{X}$ yang menjadi objek studi ini.

\section{HASIL DAN PEMBAHASAN}

Hasil perencanaan untuk keperluan AC di Lantai 1 dan di Lantai 2 masingmasing ditunjukkan pada Tabel 1 dan 2 di bawah ini:

\begin{tabular}{|c|c|c|c|}
\hline \multirow[t]{2}{*}{$\begin{array}{l}\text { Nama } \\
\text { Ruangan }\end{array}$} & \multicolumn{3}{|c|}{$\begin{array}{c}\text { Jumlah Unit \& Kapasitas AC } \\
\text { yang diperlukan }\end{array}$} \\
\hline & AC split & $\begin{array}{c}\mathrm{AC} \\
\text { standing }\end{array}$ & $\begin{array}{c}\mathrm{AC} \\
\text { cassette }\end{array}$ \\
\hline $\begin{array}{l}\text { R Palayanan } \\
\text { Terpadu R. } \\
\text { ATK Lt. } 1\end{array}$ & $\begin{array}{l}1 \times 2 \\
\text { pk }\end{array}$ & $1 \times 3 \mathrm{pk}$ & $\mathrm{x}$ \\
\hline $\begin{array}{l}\text { R. Pos } \\
\text { Sekuriti }\end{array}$ & $\begin{array}{l}1 \times 0,5 \\
\mathrm{pk}\end{array}$ & $\mathrm{X}$ & $\mathrm{X}$ \\
\hline $\begin{array}{l}\text { R. Kabid } \\
\text { Penilaian }\end{array}$ & $\begin{array}{l}1 \times 0,5 \\
\mathrm{pk}\end{array}$ & $\mathrm{x}$ & $\mathrm{X}$ \\
\hline $\begin{array}{l}\text { R. Kabid } \\
\text { PKN }\end{array}$ & $\begin{array}{l}1 \times 0,75 \\
\mathrm{pk}\end{array}$ & $\mathrm{x}$ & $\mathrm{X}$ \\
\hline $\begin{array}{l}\text { R Bidang } \\
\text { Penilaian }\end{array}$ & $1 \times 2 \mathrm{pk}$ & $\mathrm{x}$ & $\mathrm{X}$ \\
\hline $\begin{array}{l}\text { R. Bidang } \\
\text { PKN }\end{array}$ & $\begin{array}{l}1 \times 2,5 \\
\mathrm{pk}\end{array}$ & $\mathrm{x}$ & $\mathrm{X}$ \\
\hline R. Mushollo & $\begin{array}{l}1 \times 0,5 \\
\mathrm{pk}\end{array}$ & $\mathrm{X}$ & $\mathrm{X}$ \\
\hline $\begin{array}{l}\text { R. Aula } \\
\text { depan } \\
\text { Mushollo }\end{array}$ & $\begin{array}{l}1 \times 0,5 \\
\mathrm{pk}\end{array}$ & $\mathrm{X}$ & $\mathrm{X}$ \\
\hline R. Server & $\begin{array}{l}1 \times 0,5 \\
\mathrm{pk}\end{array}$ & $\mathrm{X}$ & $\mathrm{X}$ \\
\hline $\begin{array}{l}\text { R. Area } \\
\text { Tangga } \\
\text { dekat Front } \\
\text { Liner Lt.1 }\end{array}$ & $1 \times 2 \mathrm{pk}$ & $\mathrm{X}$ & $\mathrm{X}$ \\
\hline $\begin{array}{l}\text { R. Hall di } \\
\text { pintu masuk } \\
\text { samping }\end{array}$ & $1 \times 2 \mathrm{pk}$ & $\mathrm{X}$ & $X$ \\
\hline \multirow{2}{*}{$\begin{array}{l}\text { Gedung } \\
\text { Serbaguna }\end{array}$} & $3 \times 1 \mathrm{pk}$ & $1 \times 2 \mathrm{pk}$ & $\mathrm{X}$ \\
\hline & $5 \times 1 \mathrm{pk}$ & $\mathrm{x}$ & $X$ \\
\hline
\end{tabular}

Tabel 1: Perencanaan AC di Lantai 1 
Tabel 2: Perencanaan AC di Lantai 2

\begin{tabular}{|c|c|c|c|}
\hline \multirow[t]{3}{*}{$\begin{array}{l}\text { Nama } \\
\text { Ruangan }\end{array}$} & \multicolumn{3}{|c|}{$\begin{array}{c}\text { Jumlah Unit \& Kapasitas AC } \\
\text { yang diperlukan }\end{array}$} \\
\hline & AC split & $\begin{array}{c}\text { AC } \\
\text { standing }\end{array}$ & $\begin{array}{c}\mathrm{AC} \\
\text { cassette }\end{array}$ \\
\hline & $5 \times 1 \mathrm{pk}$ & $\mathrm{X}$ & $\mathrm{X}$ \\
\hline R. Kakanwil & $2 \times 2 \mathrm{pk}$ & $\mathrm{x}$ & $\mathrm{X}$ \\
\hline $\begin{array}{l}\text { R. Istirahat } \\
\text { Kakanwil }\end{array}$ & $1 \times 1 \mathrm{pk}$ & $\mathrm{x}$ & $\mathrm{X}$ \\
\hline $\begin{array}{l}\text { R.Rapat } \\
\text { dekat } \\
\text { R.Kakanwil }\end{array}$ & $\begin{array}{l}1 \times 1,5 \\
\text { pk }\end{array}$ & $\mathrm{x}$ & $X$ \\
\hline $\begin{array}{l}\text { R. Sekretaris } \\
\text { \& R.Tunggu }\end{array}$ & $1 \times 2 \mathrm{pk}$ & $\mathrm{x}$ & $X$ \\
\hline $\begin{array}{l}\text { R. Kabid } \\
\text { Umum }\end{array}$ & $\begin{array}{l}1 \times 1,5 \\
\mathrm{pk}\end{array}$ & $\mathrm{x}$ & $\mathrm{X}$ \\
\hline $\begin{array}{l}\text { R. Staf } \\
\text { Bidang } \\
\text { Umum }\end{array}$ & $\begin{array}{l}1 \times 2,5 \\
\mathrm{pk}\end{array}$ & $\mathrm{x}$ & $\mathrm{X}$ \\
\hline $\begin{array}{l}\text { R. Kabid } \\
\text { Piutang } \\
\text { Negara }\end{array}$ & $\begin{array}{l}1 \times 0,75 \\
\mathrm{pk}\end{array}$ & $\mathrm{x}$ & $\mathrm{X}$ \\
\hline $\begin{array}{l}\text { R. Staf } \\
\text { bidang } \\
\text { Piutang } \\
\text { Negara }\end{array}$ & $1 \times 2 p k$ & $\mathrm{x}$ & $\mathrm{X}$ \\
\hline $\begin{array}{l}\text { R. Kabid } \\
\text { KIHI }\end{array}$ & $\begin{array}{l}1 \times 0,75 \\
\mathrm{pk}\end{array}$ & $\mathrm{x}$ & $X$ \\
\hline $\begin{array}{l}\text { R. Staf } \\
\text { Bidang KIHI }\end{array}$ & $1 \times 2 \mathrm{pk}$ & $\mathrm{x}$ & $\mathrm{X}$ \\
\hline R. Bendahara & $\begin{array}{l}1 \times 0,5 \\
\mathrm{pk}\end{array}$ & $\mathrm{x}$ & $X$ \\
\hline $\begin{array}{l}\text { R. Kabid } \\
\text { Lelang }\end{array}$ & $1 \times 1 \mathrm{pk}$ & $\mathrm{x}$ & $X$ \\
\hline $\begin{array}{l}\text { R. Staf } \\
\text { Bidang } \\
\text { Lelang }\end{array}$ & $\begin{array}{l}1 \times 2,5 \\
\mathrm{pk}\end{array}$ & $\mathrm{x}$ & $X$ \\
\hline $\begin{array}{l}\text { R. Coffee } \\
\text { Break }\end{array}$ & $\begin{array}{l}1 \times 1,5 \\
\mathrm{pk}\end{array}$ & $\mathrm{x}$ & $\mathrm{X}$ \\
\hline $\begin{array}{l}\text { R. Rapat } \\
\text { Umum }\end{array}$ & $\mathrm{x}$ & $\mathrm{x}$ & $\begin{array}{c}2 \times 2,5 \\
\mathrm{pk}\end{array}$ \\
\hline
\end{tabular}

Penentuan jenis AC yang dipakai pada tiap ruangan terutama tergantung kepada luas dan fungsi ruangan serta jumlah penghuni yang mungkin berada di ruangan tersebut.

Penggunaan suatu jenis lampu dan jumlahnya di dalam suatu ruangan juga mempengaruhi kapasitas AC yang akan dipasang. Panas yang bersumber dari lampu jelas akan mempengaruhi tinggi rendahnya suhu di dalam ruangan. Jumlah titik lampu dan jenis lampu yang digunakan pada studi ini ditampilkan pada Tabel 3 dan Tabel 4.

Tabel 3: Jumlah Armatur dan Jenis

Lampu di

Lantai 1

\begin{tabular}{|c|c|c|c|}
\hline No & Ruang & $\mathbf{n}$ & JenisLampu \\
\hline \multirow[b]{2}{*}{1} & \multirow{2}{*}{$\begin{array}{l}\text { Ruang Area } \\
\text { PelayananTerpad } \\
\text { u, Front Liner, } \\
\text { ATK. }\end{array}$} & 4 & TL $4 \times 40 \mathrm{~W}$ \\
\hline & & 13 & $\begin{array}{l}\text { DownLight } 1 \mathrm{x} \\
40 \mathrm{~W}\end{array}$ \\
\hline \multirow[t]{2}{*}{2} & \multirow{2}{*}{$\begin{array}{l}\text { Ruang Kabid dan } \\
\text { Staf untuk } \\
\text { Bidang PKN dan } \\
\text { Penilaian }\end{array}$} & 8 & $\mathrm{TL} 4 \times 40 \mathrm{~W}$ \\
\hline & & 11 & $\begin{array}{l}\text { DownLight } 1 \\
\text { x } 30 \mathrm{~W}\end{array}$ \\
\hline 3 & Ruang Mushola & 2 & $\begin{array}{l}\text { DownLight } 1 \mathrm{x} \\
20 \mathrm{~W}\end{array}$ \\
\hline 4 & Toilet pria & 3 & $\begin{array}{l}\text { DownLight } 1 \mathrm{x} \\
20 \mathrm{~W}\end{array}$ \\
\hline 5 & Toilet wanita & 3 & $\begin{array}{l}\text { DownLight } 1 \mathrm{x} \\
20 \mathrm{~W}\end{array}$ \\
\hline 6 & $\begin{array}{l}\text { Ruang aula di } \\
\text { depanmushola }\end{array}$ & 2 & $\begin{array}{l}\text { DownLight } 1 \mathrm{x} \\
20 \mathrm{~W}\end{array}$ \\
\hline 7 & $\begin{array}{l}\text { Ruang toilet } \\
\text { umum dan } \\
\text { laktasi }\end{array}$ & 3 & $\begin{array}{l}\text { DownLight } 1 \mathrm{x} \\
20 \mathrm{~W}\end{array}$ \\
\hline 8 & $\begin{array}{l}\text { Ruang pos } \\
\text { sekuriti }\end{array}$ & 2 & $\begin{array}{l}\text { DownLight } 1 \mathrm{x} \\
20 \mathrm{~W}\end{array}$ \\
\hline 9 & $\begin{array}{l}\text { Ruang pantry } \\
\text { dan gudang }\end{array}$ & 3 & $\begin{array}{l}\text { DownLight } 1 \mathrm{x} \\
30 \mathrm{~W}\end{array}$ \\
\hline 10 & Ruang hall & 11 & $\begin{array}{l}\text { DownLight } 1 \mathrm{x} \\
20 \mathrm{~W}\end{array}$ \\
\hline 11 & $\begin{array}{l}\text { Ruang hall dan } \\
\text { server }\end{array}$ & 2 & TL 2 x $40 \mathrm{~W}$ \\
\hline 12 & $\begin{array}{l}\text { Ruang utama } \\
\text { gedung } \\
\text { Serbaguna }\end{array}$ & 4 & $\begin{array}{l}1 \times \text { XPI T- } \\
400 W\end{array}$ \\
\hline 13 & $\begin{array}{l}\text { Ruang gudang } \\
\text { gedung } \\
\text { Serbaguna }\end{array}$ & 1 & TL $2 \times 40 \mathrm{~W}$ \\
\hline 14 & $\begin{array}{l}\text { Lorong laluan } \\
\text { samping }\end{array}$ & 8 & TL $2 \times 40 \mathrm{~W}$ \\
\hline 15 & $\begin{array}{l}\text { Lampu hias di } \\
\text { lorong }\end{array}$ & 8 & $\begin{array}{l}\text { Philips outdoor } \\
\text { classic } 15338 \\
-1 \text { x } 24 \text { watt }\end{array}$ \\
\hline
\end{tabular}

Setiap jenis lampu mempumyai flux cahaya standar masing-masing. Sebagai contoh untuk lampu TL $2 \times 40 \quad$ W mempunyai flux sebesar 6000 lumen, 
dan lampu downlight 1x30 W mempunyai flux sebesar 2700 lumen. Flux cahaya ada hubungannya dengan intensitas penerangan atau iluminasi $\mathrm{E}$ seperti yang dinyatakan di persamaan (2). Sesuai dengan fungsi ruangan, maka dalam studi ini ditetapkan iluminasiiluminasinya yang antara lain adalah 370 lux, 275 lux, 230 lux, 150 lux,dan 125 lux

Tabel 4: Jumlah Armatur dan Jenis Lampu di

Lantai 2

\begin{tabular}{|c|l|c|l|}
\hline No. & \multicolumn{1}{|c|}{ Ruang } & n & JenisLampu \\
\hline 1 & Ruang Kakanwil & 24 & $\begin{array}{l}\text { DownLight } \\
1 \text { x 30W }\end{array}$ \\
\hline 2 & $\begin{array}{l}\text { Ruang istirahat } \\
\text { Kakanwil }\end{array}$ & 2 & $\begin{array}{l}\text { DownLight 1 } \\
\text { x 30W }\end{array}$ \\
\hline 3 & $\begin{array}{l}\text { Ruang toilet } \\
\text { Kakanwil }\end{array}$ & 1 & $\begin{array}{l}\text { DownLight 1 } \\
\text { x 30 W }\end{array}$ \\
\hline 4 & $\begin{array}{l}\text { Ruang Rapat } \\
\text { Kakanwil }\end{array}$ & 5 & $\begin{array}{l}\text { DownLight 1 } \\
\text { x 40W }\end{array}$ \\
\hline 5 & $\begin{array}{l}\text { Ruang } \\
\text { Sekretaris dan } \\
\text { pantry }\end{array}$ & 9 & $\begin{array}{l}\text { DownLight 1 } \\
\text { x 40W }\end{array}$ \\
\hline 6 & $\begin{array}{l}\text { Ruang Kabid } \\
\text { Umum }\end{array}$ & 5 & $\begin{array}{l}\text { DownLight 1 } \\
\text { x 40W }\end{array}$ \\
\hline 7 & $\begin{array}{l}\text { Ruang menuju } \\
\text { tangga depan } \\
\text { Kabid Umum }\end{array}$ & 3 & $\begin{array}{l}\text { DownLight 1 } \\
\text { x 20W }\end{array}$ \\
\hline 8 & $\begin{array}{l}\text { Ruang Bidang } \\
\text { Piutang Negara, } \\
\text { R. Bidang KIHI, } \\
\text { dan R. Kabid }\end{array}$ & 4 & $\begin{array}{l}\text { DownLight 1 } \\
\text { x 60W }\end{array}$ \\
\hline 9 & $\begin{array}{l}\text { Ruang Bidang } \\
\text { Lelang dan } \\
\text { Kabid, R. ATK, } \\
\text { R.Bendahara, } \\
\text { R.Coffe Break, } \\
\text { serta lorong }\end{array}$ & 10 & $\begin{array}{l}\text { DownLight 1 } \\
\text { x 40W }\end{array}$ \\
\cline { 2 - 4 } TL 4 x 40 W \\
\hline 10 & $\begin{array}{l}\text { Ruang toilet } \\
\text { DownLight 1 } \\
\text { x 40W }\end{array}$ \\
\hline 11 & $\begin{array}{l}\text { Ruang Rapat } \\
\text { Umum }\end{array}$ & 4 & $\begin{array}{l}\text { DownLight 1 } \\
\text { x 20 W }\end{array}$ \\
\cline { 3 - 4 } TL 4 x 40 W \\
\hline
\end{tabular}

Berdasarkan data yang didapatkan di lapangan, diketahui bahwa luas bangunan gedung Kantor X untuk lantai 1 dan lantai 2 masing-masing adalah $490,5 \mathrm{~m}^{2}$ dan $474,5 \mathrm{~m} 2$, jangka waktu penggunaan air adalah 8 jam perharii, serta jumlah/beban penghuni adalah 70 orang. Dengan menggunakan persamaan-persamaan (4) sampai (11) serta kecepatan aliran air (v) di dalam pipa sebesar $1,12 \mathrm{~m} /$ detik maka didapat:

- Pemakaian air rata-rata per-jam 1,05 $\mathrm{m}^{3} / \mathrm{jam}$

- Kapasitas tanki air atas efektif sebesar $1,4 \mathrm{~m}^{3}$

Ukuran pipa air dari pompa di ruang pompa pada dasar bangunan ke tanki atas adalah 2 inchi.

\section{KESIMPULAN}

Perencanaan sistem mekanikal elektrikal plumbing (MEP) gedung Kantor X telah menggambarkan bahwa banyak faktor yang harus diperhitungkan dalam perencanaan sistem MEP ini, makin tinggi atau banyak lantai gedung yang dibangun maka akan semakin rumit pula perencanaannya. Dengan rumitnya perencanaan, maka disitulah bergunanya perumusan yang standar yang harus diikuti oleh semua pihak terutama konsultan perencana bangunan gedung tersebut.

\section{REFERENSI}

[1] Rogelio Palomera-Arias, Rui Liu, Mechanical, Electrical and Plumbing Systems in Construction Management: A Literature Review of Existing MEP Textbooks. $122^{\text {nd }}$ ASEE Annual Conference \& Exposition, Seatle Washington, 2015

[2] Suhardianto. 2016. Perancangan Sistem Plambing Instalasi Air Bersih dan Air Buangan pada Pembangunan Gedung Perkantoran Bertingkat Tujuh Lantai. Jurnal Teknik Mesin, Vol. 5(3).

[3] Pan Ji, Jeffrey Parks, Marc A. Edwards, Amy Pruden. 2015. Impact of Water Chemistry, Pipe Material and Stagnation on the Building Plumbing Microbiome. 
PLOS ONE Journal/ doi.org/10.1371/journal.pone.

[4] Laxmi C. Gupta, dan Samruddhi Thawari. 2016. Plumbing System in High Rise Building.International Journal for Innovative Research in Science \& Technology, Volume 2 (11).

[5] Semuel J. Kalukar, Hans Tumaliang, dan Maickel Tuegeh. 2015. Desain Instalasi Penerangan pada Bangunan Multi Fungsi. E-journal Teknik Elektro dan Komputer, Volume 4(3).

[6] Feri Diana, dan Anita Hidayati, 2014. Analisa Perhitungan untuk Kebutuhan Penerangan di Bangunan Rig Raisis Berbasis Visual Basic. Kapal, Volume 11(1).

[7] Nurul Jamala. 2017. The effect of building façade on natural lighting. AIP Conference Proceedings pp.1831.

[8] Wahyu Priatna, dan Ary Bachtiar Krishna Putra. 2016. Perencanaan Ulang Sistem Pengkondisian Udara Gedung Surabaya Suite Hotel di Surabaya.Jurnal TEKNIK ITS Vol. 5 No. 2.

[9] Atthaillah, Iqbal, dan Saputra Situmeang. 2017. Simulasi Pencahayaan Alami untuk Gedung PS Arsitektur Universitas Malikussaleh. Jurnal Arsitektur, Volume 16 No. 2. 